\title{
Ajuste de expectativas tras la COVID-19
}

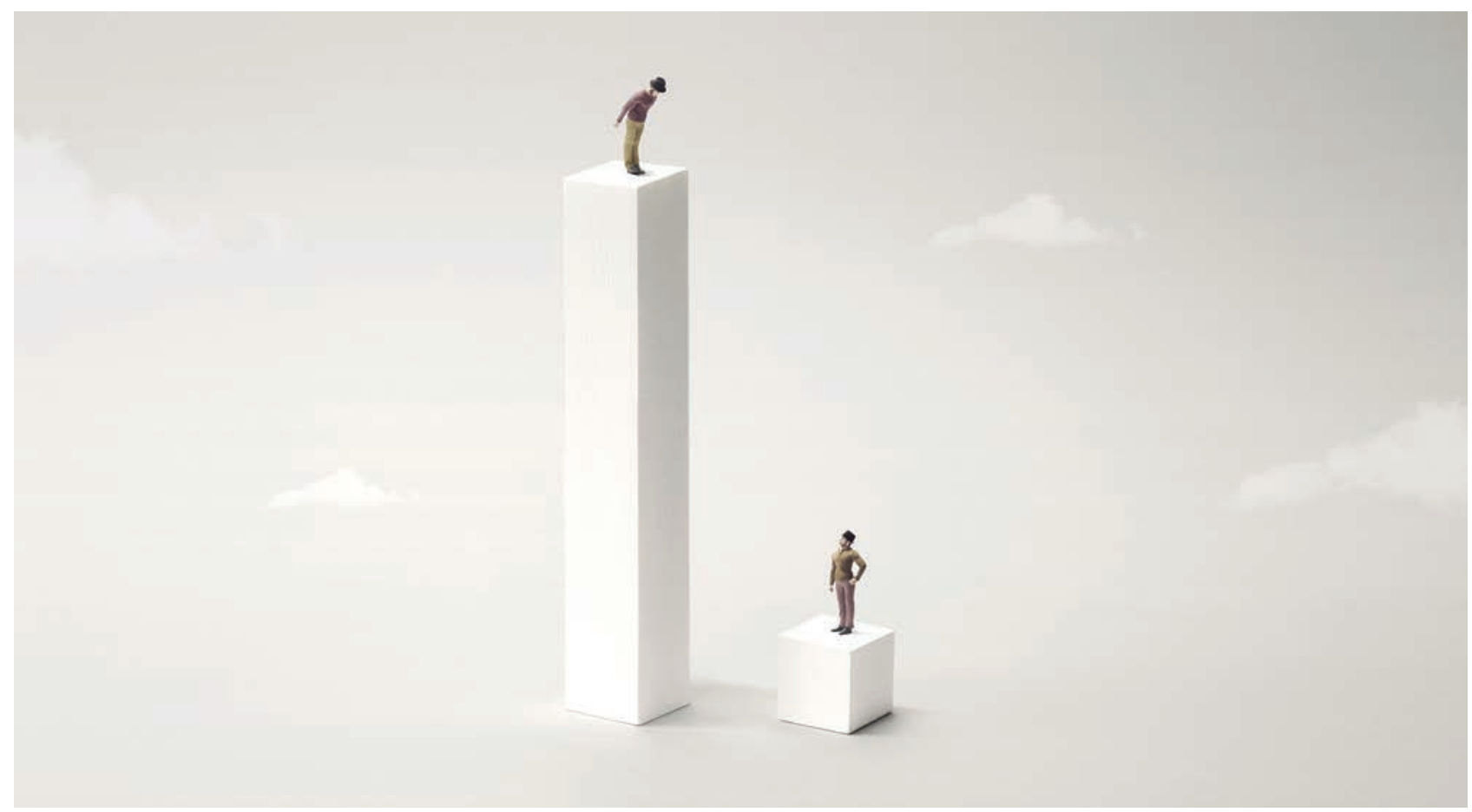

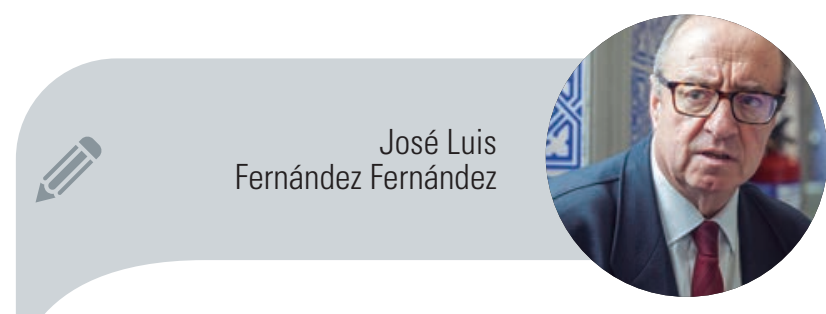

Cátedra Iberdrola de Ética Económica y Empresaria Universidad Pontificia Comillas - ICADE jlfernandez@icade.comillas.edu

Desconfío del celo indiscreto; nunca me sentí a gusto con el voluntarismo; siento una aversión congénita ante los proyectos quiméricos y los arbitristas, por más que esté dispuesto a concederles la dosis de buena voluntad que se quiera suponer a sus propuestas. Huyo como de Belcebú de los iluminados que analizan con simplismo la realidad y entonces, o bien se transmutan en profetas de calamidades y aturden con anticipaciones jeremíacas del Valle de Josafat; o bien, lirio en una mano y el borrador en la otra, tratan de vendernos el discurso huero de que: "¡Aquí no ha pasado nada! ¡Borrón, cuenta nueva y a otra cosa!".

Para acabar de convenir las coordenadas en esta suerte de formularium terminorum de inclinaciones y contraquerencias, añado que en absoluto me resig- no a militar bajo la bandera de los crédulos cofrades que sueñan con la posibilidad de que se produzcan transformaciones radicales, saltos cualitativos, metamorfosis revolucionarias, como por ensalmo y de un día para otro. Cierto es que no descarto por imposibilidad ontológica la metanoia. Estoy dispuesto a conceder la virtualidad de tal o cual caída del caballo, en el camino a Damasco, en la singladura a Nueva York, en el vagabundaje por úbeda y sus cerros... Lo que acepto como axioma es la infrecuencia de tal circunstancia.

Por ello, tiendo a percibir como mantras inanes algunas afirmaciones que empiezan a resultarme tópicos. Bienintencionados, sí; pero manidos. Como lugares comunes con muy escaso fundamento in re. Léanse, verbi gratia, las siguientes tesis cazadas al vuelo en medios y redes sociales durante las semanas de reclusión: "De esta crisis saldremos todos juntos o no saldrá ninguno". "El día después seremos todos mucho mejores y mucho más fuertes". "Va a haber un antes y un después". "Nada va a ser igual a partir de ahora". "Habremos aprendido la lección y a vivir de otra manera, a respetarnos y a cuidar más los unos de los otros"...

Como proyección de deseos no están mal. Pero, como profecías, ¿en qué se basan? ¿Qué fundamento tienen? Porque torres más altas cayeron en el siglo XX, con un rosario interminable de conflic- 


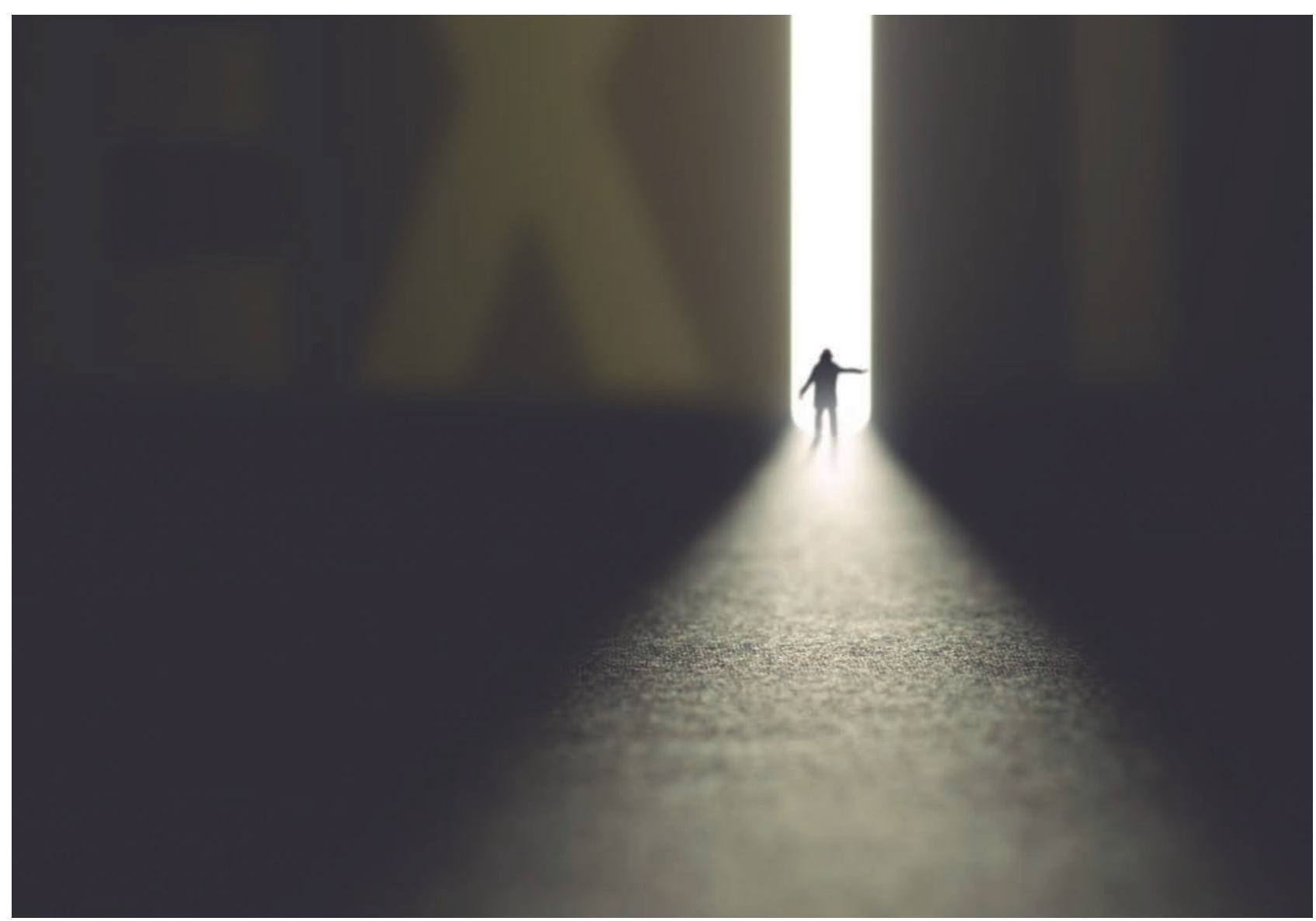

tos bélicos; un cúmulo vergonzoso de despropósitos contra Dios y contra los hombres; un par de guerras mundiales de añadidura; $y$, por hacer el cuento corto, el drama del Holocausto, la vergüenza de la Shoah, como una de las mayores lacras que anotar en el debe de lo humano... Y bien, ¿qué sacamos en claro de todo ello? Sería inapropiado decir que nada; pero resultaría pretencioso afirmar que fue mucho lo que aprendimos. Sobre todo si juzgamos por referencia a la praxis y si tomamos en consideración la abrumadora agenda que nos espera para los próximos años en el horizonte del 2030.

Digamos, promediando, que, de los errores, de las malas prácticas y de los dislates del pasado hemos aprendido lo justo: ni más ni menos. Por consiguiente, tras la pandemia del Sars-CoV-2, que tuvo confinado a medio mundo varias semanas, convendría articular un discurso que huya tanto del triunfalismo y de la fantasía de omnipotencia, cuanto del sentimiento de impotencia derrotista y desconsolado.

Habríamos de intentar construir entre todos un relato posibilista que, en cierta forma, pudiere acabar teniendo incidencia real e impacto tangible en la transformación de algunas de las estructuras que engranan la dinámica del mundo globalizado; para, desde ahí, acabar afectando en positivo a la vida de las personas, al progreso de los pueblos y a la dignidad de los más desfavorecidos.
Para ello, se precisa mantener con buen pulso una tensión dialéctica, donde, de una parte, apuntemos a lo alto para mantener el goniómetro con el alza de mira puesta en lo utópico —el heroísmo, la solidaridad, el amor...-; y donde, al propio tiempo, se esté siempre llevando a efecto un ajuste ecuánime de expectativas. Algo se habrá avanzado si, de una parte, somos capaces de identificar el inmediato objetivo a batir y si, de otra, aceptamos como bueno el hecho de caminar e/ siguiente paso posible. Con estos pertrechos, nos habríamos inmunizado frente a las frustraciones y los desencantos que habrán de seguir a la constatación de que, semanas después de habernos levantado el confinamiento, estaremos de nuevo en las mismas, habremos vuelto a las andadas, al business as usual y, ahora sí, al "jaquí no ha pasado nada!"...

Sería triste constatar, resignados, la pérdida de una oportunidad de oro para habernos replanteado a fondo muchas cosas y la esencia de múltiples quehaceres. Para empezar, todos los modelos de negocio. Y por lo que más directamente nos afecta, la enseñanza. El ámbito y la significación de su propósito. Los contenidos, los métodos e instrumentos. Y, sobre todo, la relación docente-discente en los adecuados marcos institucionales, capaces de estructurar una educación al servicio de la persona, en busca del bien y animada por la verdad 